\title{
Efficacy of Phenobarbital in Neonatal Seizures
}

\author{
C.B. Van Orman and H.Z. Darwish
}

\begin{abstract}
A retrospective study of neonatal seizures in a tertiary care neonatal intensive care unit determined a $3.2 \%$ incidence, and confirmed the relatively poor efficacy of the traditional anticonvulsants phenobarbital and phenytoin. Only $33 \%$ responded to an initial adequate loading dose of phenobarbital, while $56 \%$ responded to either or both anticonvulsants. Although multifocal clonic seizures were most common (42\%), tonic seizures were next in freqency $(30 \%)$. Tonic seizures which did not respond to phenobarbital responded quite poorly to the addition of phenytoin compared to other seizure types. Tonic seizures may be the result of brainstem release phenomena and require a different strategy for management. Among nonresponders in this study, there was a $56 \%$ mortality rate but only $33 \%$ of responders died. There is a critical need for studies to find more efficacious agents than phenobarbital and phenytoin to treat seizures in the newborn.
\end{abstract}

RÉSUMÉ: L'efficacité de phénobarbital contre des convulsions néo-natales Nous avons étudié rétrospectivement des convulsions néo-natales chez un centre de soins tertiaires néo-natales. On a verifié la relativement mauvaise efficacité des anticonvulsivants traditionnels, le phénobarbital et la phéytoïne. Seulement 33 pour cent des témoins ont réagi au dosage initial suffisant de phénobarbital, tandis que 56 pour cent ont réagis à l'une ou à les deux anticonvulsivants. Bien que des convulsions cloniques multifocales étaient les plus fréquentes $(42 \%)$, des convulsions toniques se trouvèrent les prochaines en fréquence (30\%). Les convulsions toniques en contraste avec les autres types de convulsions, n'ont pas réagi au phénobarbital et ont également reagi très peu en ajoutant la phénytoïne. Des convulsions toniques peuvent être le résultat d'un phénomène de liberation du tronc cérébral, nécessitant une autre approche différente de traitement. Parmi les enfants qui n'ont pas réagi dans cette étude, il y avait un taux de mortalité de 56 pour cent, cependant seulement 33 pour cent de ceux qui ont réagi sont décédés. Il y existe un besoin d’études supplémentaires pour retrouver d'autres drogues plus efficaces que le phénobarbital et la phénytoïne pour traiter des convulsions chez le nouveau-né.

Can. J. Neurol. Sci. 1985: 12:95.99

Seizures in the neonatal period are a common problem. Recent estimates suggest an incidence of 1.5 to 5.5 per 1000 live births. ${ }^{1,2}$ Aetiologies are multiple and, to a large extent, determine the outcome. ${ }^{3-5}$ Follow-up studies of infants who had neonatal seizures indicate that whereas $50 \%$ develop normally, $30 \%$ are neurologically abnormal and $20 \%$ die. ${ }^{6-8}$ Among survivors, recurrent seizures starting in later infancy or childhood occur in $17-25 \% .^{6,9}$ Analysis of risk factors recognized in the perinatal period shows the presence of neonatal seizures to be one of the most potent predictors of severe neurological handicap. ${ }^{\text {I. } 11}$

A recent survey confirmed phenobarbital to be the preferred initial drug in the treatment of neonatal seizures for all neonatologist respondents and for $96 \%$ of paediatric neurologists. ${ }^{12}$ Published studies reporting the efficacy of phenobarbital have yielded widely conflicting results. Painter et al ${ }^{13,{ }^{14}}$ found only $36 \%$ of neonates with seizures responded to phenobarbital alone and Lockman et al controlled seizure activity with phenobarbital alone in $32 \%$ of neonates. ${ }^{15}$ However, since Gal et al reported that seizure control was achieved with phenobarbital monotherapy in $85 \%$ of neonates, ${ }^{16}$ we were spurred to examine our own experience with neonatal seizures retrospectively to attempt to determine the efficacy of phenobarbital.

\section{Materials AND MethodS}

One hundred forty two neonates with seizures admitted to a single tertiary care neonatal intensive care unit (NICU) during the years 1977 to 1983 were included in this review. Hospital records were reviewed to verify the diagnosis of seizures and to ascertain the single most likely cause. These decisions were usually made at the time of the seizures by a consulting paediatric neurologist and were usually based on the clinical features. Ictal EEG correlation was not always obtained.

Infants were included in the review if there was a firm clinical diagnosis of seizures with onset in the first 28 days of life, and an adequate loading dose of anticonvulsant was used. Eighty eight infants met the criteria for inclusion. Of the 88 patients included, 34 received a single intravenous bolus of $15 \mathrm{mg} / \mathrm{kg}$ or more of either phenobarbital or phenytoin. The remaining $\mathbf{5 0}$ infants received $15 \mathrm{mg} / \mathrm{kg}$ or more of either anticonvulsant in 
multiple smaller intravenous doses within the first 24 hours of the initial dose. Patients were excluded if there was uncertainty about the diagnosis of neonatal seizures or an inadequate loading dose of anticonvulsant given. Four infants with proved infectious disease and five with metabolic disorders causing seizures were excluded. Data regarding sex, gestational age, birth weight, Apgar scores ( 1 and 5 minutes), and single most probable aetiology were reviewed. We utilized Volpe's classification of subtle, generalized tonic, multifocal clonic, focal clonic and myoclonic neonatal seizures. ${ }^{8}$ The time of seizure onset, seizure frequency and duration of seizure activity before control were noted. The anticonvulsant used and dosages administered (loading and maintenance), and response to anticonvulsants were reviewed. A responder ( $R$ ) was identified as an infant who ceased all seizure activity within 2 hours of receiving the adequate loading dose of the anticonvulsant(s). A partial response to anticonvulsant could not be assessed reliably because of the retrospective nature of the study.

\section{RESULTS}

$3.2 \%$ of all infants admitted to the NICU in the 7 year study period had seizures in the neonatal period. The study population $(\mathrm{n}=88)$ was characterized by a mean gestational age of $35 \pm 5.7$ weeks. The mean birth weight was $2540 \pm 1120$ grams. The one minute Apgar score was $3.4 \pm 2.4$, and the five minute Apgar score was $5.7 \pm 2.5$.

The most common aetiology of the seizures was hypoxiaischaemia, in $60 \%$. Intracranial haemorrhage was present in $34 \%$, and cerebral dysgenesis in $5 \%$. The aetiology remained unknown in $1 \%$. There was no significant difference between responders and nonresponders in aetiology. (Figure 1 ).

The most common type of seizure noted was multifocal clonic in $42 \%$. Tonic seizures were next most common, occurring in $30 \%$ of the infants. We had only $15 \%$ with subtle seizures, and $12 \%$ had the focal clonic type. One infant had myoclonic seizures. 81 infants $(92 \%)$ received an initial loading dose of phenobarbital and 7 received phenytoin as the initial anticonvulsant. 40 infants (56\%) responded to either or both of the anticonvulsants. Of all patients receiving an adequate loading dose of phenobarbital $(\mathrm{n}=81)$, only $27(33 \%)$ of these neonates were controlled. (Figure 2).

On comparison of the responders and nonresponders, no significant differences were identified in sex ratio, gestational
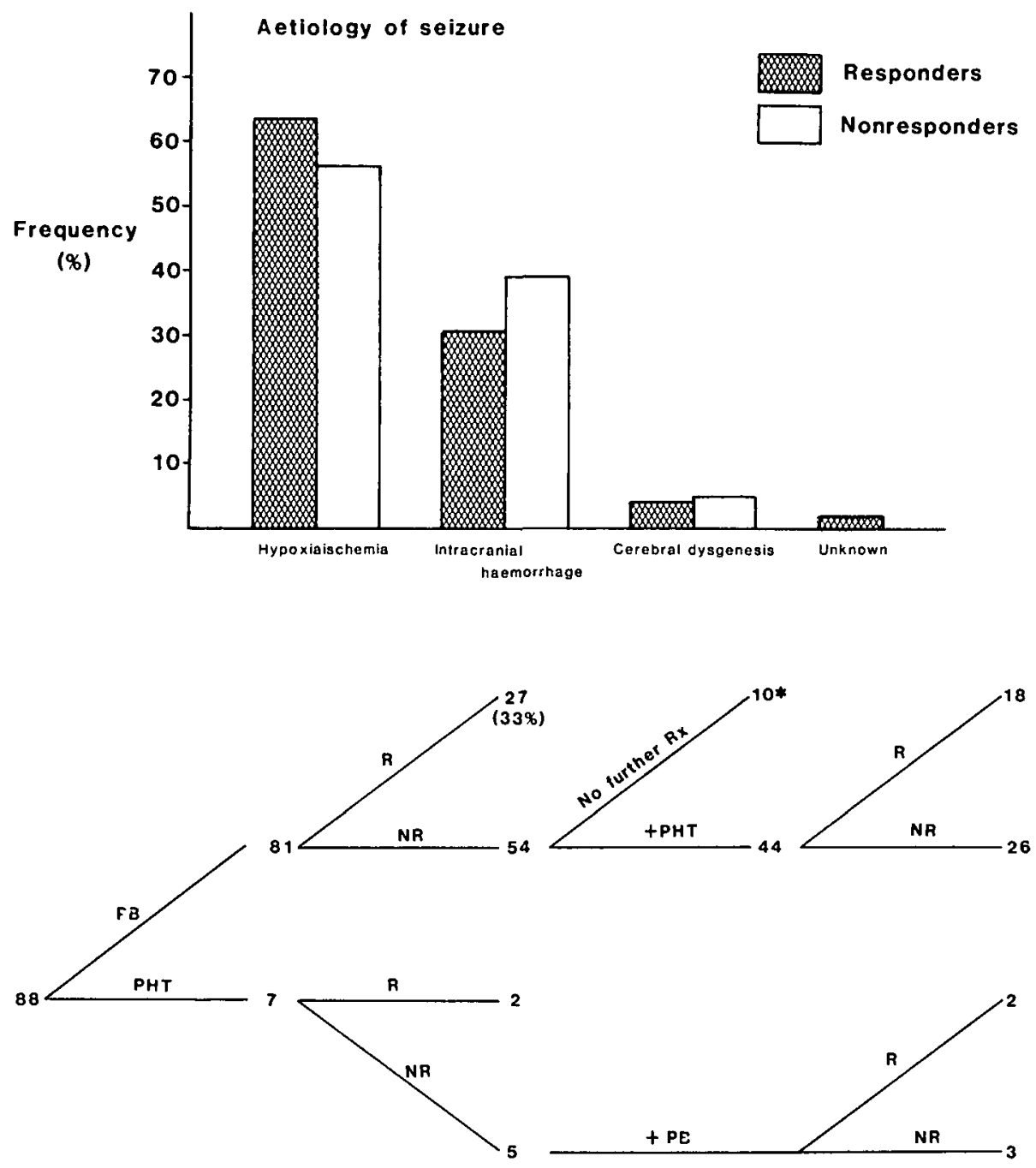

(PB-Phenobarbital, PHT-Phenytion, R=responder NR=nonresponder.

* These patients continued to seizure.)
Figure I - Comparison of seizure aetiologyand response to anticonvulsants 
age, birth weight, 1 and 5 minute Apgar scores (Table 1), or the mean loading dose of the anticonvulsant used (Figure 3). Comparison of the infants who received one single large bolus of anticonvulsant with those who reached the same criterion dose of $15 \mathrm{mg} / \mathrm{kg}$ or more after two or more doses in the first 24 hours after the initial dose, revealed no difference in response rate. $50 \%$ of those who received the single bolus and $60 \%$ of the infants who received multiple smaller doses responded. There was a significant difference in mortality with a rate of $33 \%$ among responders and $56 \%$ among nonresponders $(\mathrm{p}<0.05)$ (Figure 4).

There was no significant difference in the frequency of seizure types between the group responding to anticonvulsants and the nonresponders. When tonic seizures were compared to all other seizure types, the response of tonic seizures to anticonvulsants was quite poor. In those patients who did not respond to an adequate loading dose of phenobarbital initially, control of seizure activity was more likely to be achieved with the addition of phenytoin in patients having seizure types other than tonic $(0.1>p>0.05$ ) (Figure 5).

When the time of seizure onset was reviewed, 43 neonates (49\%) had seizure onset in the first 24 hours of life and $45(51 \%)$ had onset of seizures later. In comparing the group with onset in the first 24 hours to the later onset group, no significant difference was noted in the frequency of asphyxia or congenital malformation. The early onset group did have significantly less intracerebral haemorrhage than the group with onset after 24 hours $(p<0.05)$. Seizures with onset in the first 24 hours tended

Table 1: Comparison of responders $(R)$ to nonresponders (NR) $(\mathrm{n}=88: \mathrm{R}=49, \mathrm{NR}=39)$

\begin{tabular}{lcc}
\hline & $\underline{\mathbf{R}}$ & $\underline{\mathbf{N R}}$ \\
Male/female ratio & $1.7: 1$ & $1.8: 1$ \\
$\overline{\mathrm{X}}$ Gestational age (in weeks) & $36.6 \pm 5.7$ & $34.7 \pm 5.5$ \\
$\overline{\mathrm{X}}$ Birth weight (in grams) & $2683 \pm 1091$ & $2361 \pm 1131$ \\
$\overline{\mathrm{X}} 1$ minute Apgar score & $3.1 \pm 2.4$ & $3.8 \pm 2.5$ \\
$\overline{\mathrm{X}} 5$ minute Apgar score & $5.4 \pm 2.4$ & $6.1 \pm 2.4$ \\
\hline
\end{tabular}

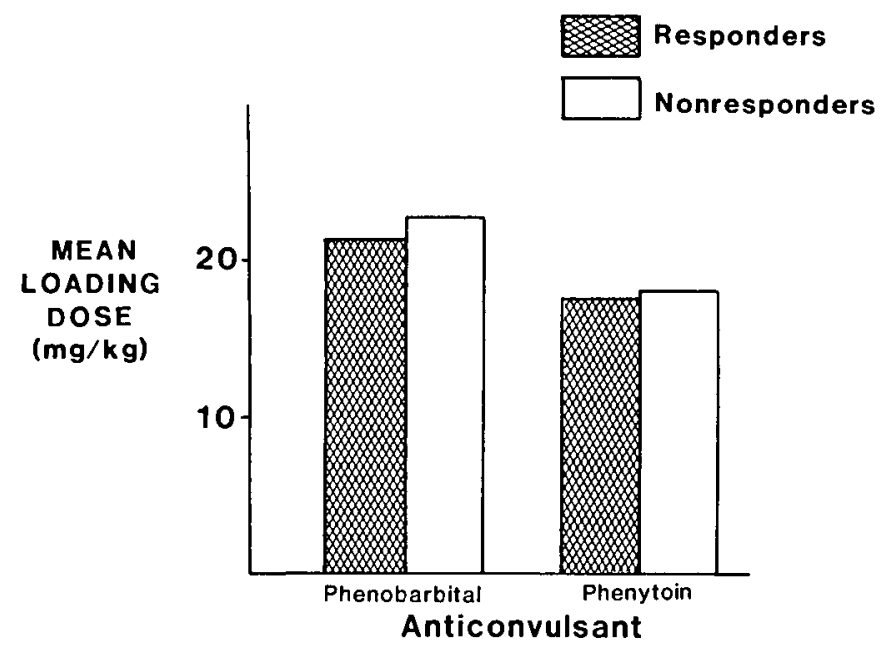

Figure 3-Mean loading doses of anticonvulsants used: Comparison of responders and monresponders to respond to anticonvulsants better than those starting later. The difference reached significance at the $10 \%$ level only among those not responding to phenobarbital. Among those infants with seizure onset in the first day of life, who failed to respond to phenobarbital $(n=24), 13(54 \%)$ responded to the addition of phenytoin, whereas among those with later onset of seizures who also had failed to respond to phenobarbital $(n=20)$, only 5 $(25 \%)$ responded to the addition of phenytoin $(0.01>p>0.05)$ (Figure 6).

\section{Discussion}

The role of neonatal seizures in aggravating pre-existing central nervous system injury remains unresolved. ${ }^{4}$, 17.18 Bergman et al, in assessing the outcome of neonates with seizures, noted that many days of neonatal seizures and increased

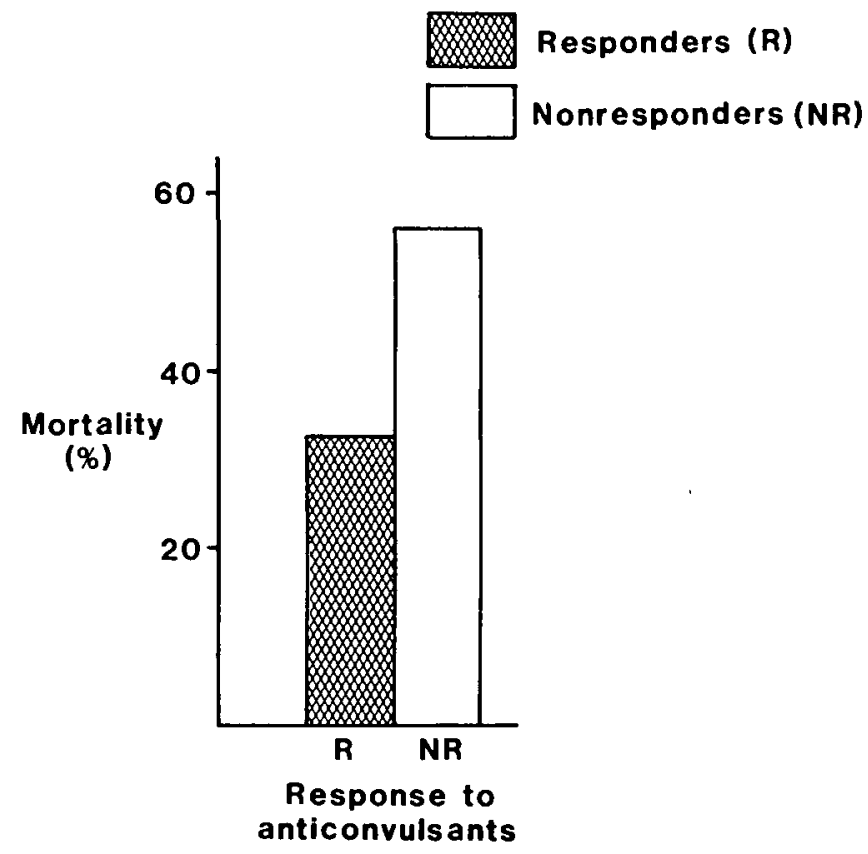

Figure $4-$ Relationship between response to anticonvulsants and morrality $(D F=1 ; P<0.05)$

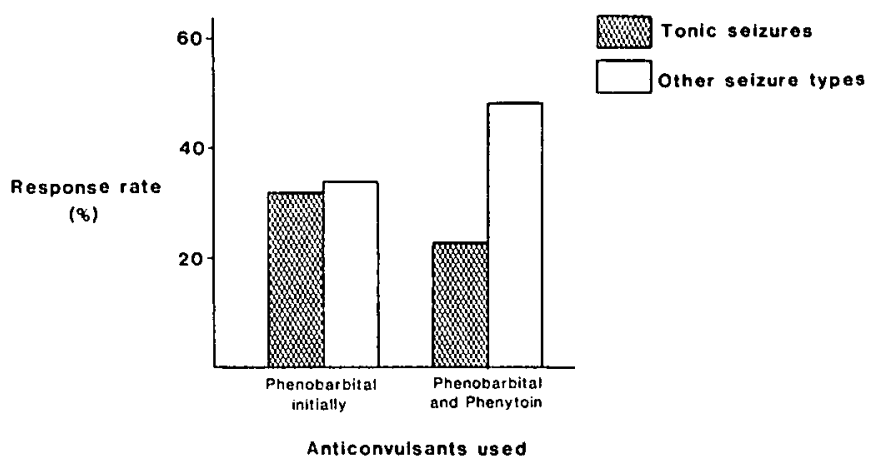

Figure 5-Comparison of response of tonic seizures and other seizure types to anticonvulsants $\left(X^{2}=3.59 ; D F=1 ; 0.1>P>0.05\right)$ 


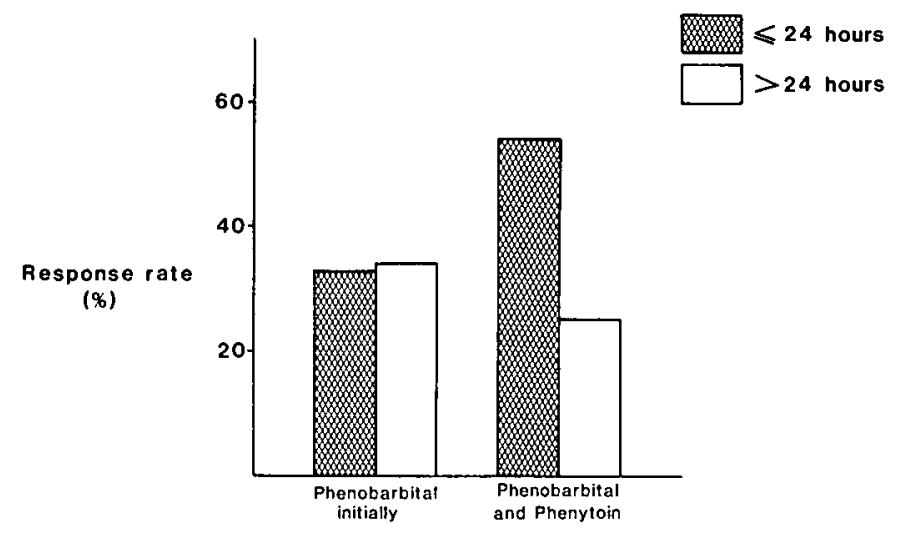

Anticonvulsants used

Figure 6 - Comparison of efficacy of anticonvulsants and time of seizure onset.

$\left(X^{2}=2.73 ; D F=1 ; 0.1>P>0.05\right)$

number of anticonvulsants used were significant factors associated with a poor outcome. ${ }^{1}$ In this study we find that continuing seizure activity is the only apparent difference between the responder and nonresponder groups accounting for the high mortality seen in the nonresponders. However, features such as the presence or absence of neurological signs before seizure onset, the associated systemic disturbances and EEG data were not uniformly available for analysis. It is possible that more severe insults were present in the nonresponders group even though there were no significant differences in gestational age, 1 and 5 minute Apgar scores, or in aetiologies of the underlying disorders between responders and nonresponders.

Studies in the immature animal model have demonstrated adverse effects of ongoing seizure activity in the developing nervous system. ${ }^{10,}{ }^{20-24}$ In the human neonate, many of the pathophysiologic mechanisms described in the animal with induced convulsions are operative. Ictal systemic hypertension and increased cerebral blood flow velocity have been demonstrated..$^{25}$ Impaired autoregulation of cerebral blood flow with seizures has also been demonstrated. ${ }^{26}$ These changes have been demonstrated even in the absence of convulsive motor activity, as in the paralyzed infant ${ }^{27}$ When such derangements occur with diminutions of transcutaneous $\mathrm{PaO}_{2},{ }^{28}$ the immature central nervous system may well be at risk for additional irreversible injury. ${ }^{28}$

We found particular difficulty in controlling tonic seizures. The infants with tonic seizures included in this study did not have massive intraventricular haemorrhage and could not be considered as examples of decerebration secondary to central transtentorial herniation. Only $23 \%$ of tonic seizures not responding to phenobarbital subsequently responded to phenytoin, whereas $48 \%$ of other seizure types did, suggesting that tonic seizures are caused by mechanisms different than other seizure types. Kellaway and Hrachovy found no EEG seizure activity in $85 \%$ of their infants with tonic seizures, and felt these represented "brainstem release" phenomena, consequent to depression of forebrain inhibitory influences. ${ }^{29}$ Unfortunately the convulsive activity in the $15 \%$ with tonic seizures and simultaneous EEG seizure activity was usually indistinguishable from the tonic seizures without EEG changes. We do not know whether tonic seizures resulting from such brainstem release phenomena may still produce the same deleterious cardiac and respiratory effects on the infant as tonic seizures with EEG seizure activity.

At present, phenobarbital is considered the first drug in treating neonatal seizures ${ }^{12}$ and most units utilize phenytoin as the second agent if seizures continue. Painter et al and Lockman et al have demonstrated that an initial intravenous dose of phenobarbital of 15 to $20 \mathrm{mg} / \mathrm{kg}$ is needed to achieve a therapeutic plasma concentration of $20 \mu \mathrm{g} / \mathrm{mL} \cdot{ }^{13-15}$ Utilizing such doses, Lockman et al noted that $32 \%$ of the neonates responded to phenobarbital alone, ${ }^{15}$ and Painter et al achieved effective seizure control with phenobarbital alone in $36 \%$ of infants, despite plasma levels of $20 \mu \mathrm{g} / \mathrm{mL}$ or higher. ${ }^{13-14}$ Surprisingly, Gal et al reported satisfactory seizure control in $85 \%$ of neonates using phenobarbital monotherapy. ${ }^{16}$ They utilized an initial loading dose of $15 \mathrm{mg} / \mathrm{kg}$ followed by additional doses of 5 to $10 \mathrm{mg} / \mathrm{kg}$ every 5 to 10 minutes, to a maximum of $40 \mathrm{mg} / \mathrm{kg}$, when seizures did not stop. The use of loading doses of $40 \mathrm{mg} / \mathrm{kg}$ of phenobarbital can be expected to achieve serum levels beyond $50 \mu \mathrm{g} / \mathrm{mL}$ in a significant number of neonates. The effects of such a level on the neonatal circulation is not clear, though an invariable cardiac deceleration to rates below 100 per minute accompanied by a decrease in beat to beat variability was reported by Svenningsen et al. ${ }^{30}$ Cardiac deceleration in the neonate is not accompanied by increased stroke volume and may produce decreased cardiac output and compromised cerebral perfusion.

In this retrospective study we could not assess the possibility of "partial" response to anticonvulsants. We report a complete response rate of phenobarbital alone in only $33 \%$ of the neonates. This is certainly consistent with the efficacy noted by Painter et al and Lockman et al. ${ }^{13-15}$ Correlation of plasma phenobarbital levels with seizure control was not possible in this retrospective review. However, no infant in the study population received an intravenous loading dose of less than $15 \mathrm{mg} / \mathrm{kg}$ and the mean loading dose among the nonresponders was $22.7 \mathrm{mg} / \mathrm{kg}$, a dosage capable of achieving plasma phenobarbital levels well above the reported minimum therapeutic level within two hours of administration. ${ }^{31}$

Despite Gal et al's results ${ }^{16}$ we, like others, find that phenobarbital, the usual first anticonvulsant utilized, will not be efficacious in the majority of cases of neonatal seizures. Studies to find alternative agents with greater efficacy have been reported. Gamstorp and $\operatorname{Sedin}^{32}$ reported on 8 term infants treated with continuous intravenous infusion of diazepam. ${ }^{32}$ Seizures stopped in all 8 subjects and did not return after discontinuation of the infusion. This leads us to speculate that lorazepam may be a more efficacious drug in neonatal seizures. Lorazepam has been found in children and adults with status epilepticus to have onset of action within fifteen minutes, and a prolonged duration of action after a single dose.$^{33}$ Moreover, it has been suggested that the benzodiazepines should be evaluated as the initial agent, not as the third anticonvulsant after phenobarbital and phenytoin, since phenytoin may have an adverse effect on the benzodiazepine receptors. ${ }^{34} \mathrm{~A}$ recent report on the use of oral primidone in the treatment of neonatal seizures unresponsive to phenobarbital and phenytoin has shown seizure control within 48 hours of initiating therapy. ${ }^{35}$

We believe that efforts to find and assess newer anticonvulsants which may have greater efficacy than phenobarbital and phenytoin in neonates with seizures should continue. We are presently planning a prospective trial with lorazepam. 


\section{REFERENCES}

1. Bergman 1, Painter MJ, Hirsch RP et al. Outcome in neonates with convulsions treated in an intensive care unit. Ann Neurol 1983: 14: 642-647.

2. Eriksson M, Zetterstrom R. Neonatal convulsions: incidence and causes in the Stockholm area. Acta Paediatr Scand 1979: 68: $807-811$.

3. Hill A. Volpe JJ. Seizures, hypoxic-ischemic brain injury, and intraventricular hemorrhage in the newborn. Ann Neurol 1981: 10: 109-121.

4. Lombroso CT (1983) Prognosis in neonatal seizures. In: Advances in Neurology, Vol. 34: Status Epilepticus. Delgado-Escueta AV, Wasterlain CG, Treiman DM, Porter RJ, eds. New York: Raven Press, 1983: 101-113.

5. Rose AL, Lombroso CT. Neonatal seizure states. Pediatrics 1970; 45: 404-425.

6. Bergman 1, Painter MJ, Crumrine PK. Neonatal seizures. Semin Perinatal 1982; 6: 54-67.

7. Lombroso CT. Convulsive disorders in newborns. In: Pediatric Neurology and Neurosurgery. Thompson RA, Green JR, eds. New York: Spectrum Publications, 1978: 205-239.

8. Volpe JJ. Neonatal seizures. N Eng J Med 1973: 289: 413-416.

9. Watanabe K. Kuroyangi M, Hara K et al. Neonatal seizures and subsequent epilepsy. Brain Dev 1982; 4: 341-346.

10. Holden KR, Mellitts ED, Freeman JM. Neonatal seizures: I. Correlation of prenatal and perinatal events with outcomes. Pediatrics 1982; 70: 165-176.

11. Nelson KB, Broman SH. Perinatal risk factors in children with serious motor and mental handicaps. Ann Neurol 1977; 2: 371-377.

12. Boer HR, Gal P. Neonatal seizures: a survey of current practice. Clin Pediatr 1982; $21: 453-457$.

13. Painter MJ. Pippenger C. MacDonald $\mathrm{H}$ et al. Phenobarbital and diphenylhydantoin levels in neonates with seizures. $J$ Pediatr 1978; 92: 315-319

14. Painter MJ, Pippenger $C$, Wasterlain $C$ et al. Phenobarbital and phenytoin in neonatal seizures: metabolism and tissue distribution. Neurology 1981: 31: 1107-1112.

15. Lockman LA, Kriel R, Zaske D et al. Phenobarbital dosage for control of neonatal seizures. Neurology 1979; 29: 1445-1449.

16. Gal P, Toback J, Boer HR et al. Efficacy of phenobarbital monotherapy in treatment of neonatal seizures - relationship to blood levels. Neurology 1982; 32: 1401-1404.

17. Mellits ED, Holden KR. Freeman JM. Neonatal seizures: II. A multivariate analysis of factors associated with outcome. Pediatrics 1982: 70: 177-185.

18. Volpe JJ. Neurology of the newborn. Philadelphia: W.B. Saunders, 1981: 111-137.

19. Delgado-Escueta AV, Wasterlain CG. Treiman DM. Porter RJ (1983). Advances in Neurology, Vol. 34: Status Epilepticus. New York: Raven Press, 1983
20. Meldrum BS, Brierley JB. Prolonged epileptic seizures in primates. Arch Neurol 1973: 28: 10-17.

21. Meldrum BS, Horton RW, Brierley JB. Epileptic brain damage in adolescent baboons following seizures induced by allylglycine. Brain 1974: 97: 407-418.

22. Wasterlain CG. Effects of neonatal status epilepticus on rat brain development. Neurology 1976: 26: 975-986.

23. Wasterlain CG. Neonatal seizures and brain growth. Neuropädiatrie 1978; 9: 213-228.

24. Wasterlain CG, Plum F. Vulnerability of developing rat brain to electroconvulsive seizures. Arch Neurol 1973: 29: 38-45.

25. Perlman JM, Volpe JJ. Seizures in the preterm infant: Effects on cerebral blood flow velocity, intracranial pressure, and arterial blood pressure. J Pediatr 1983: 102: 288-293.

26. Lou HC, Friis-Hansen B. Arterial blood pressure elevations during motor activity and epileptic seizures in the newborn. Acta Paediatr Scand 1979; 68: 803-806.

27. Lou HC, Lassen NA. Friis-Hansen B. Impaired autoregulation of cerebral blood flow in the distressed newborn infant. J Pediatr 1979; 94: 118-121.

28. Monin $\mathrm{P}$, Vert $\mathrm{P}$, Andre $\mathrm{M}$ et al. Transcutaneous $\mathrm{PO}_{2}$ monitoring in the newborn during apneic spells, convulsions, cardiac catherizations and exchange transfusions. In: Birth Defects: Original Article Series, Vol. XV, No.5. Huch A. Huch R. Lucey JF, eds. New York: Alan R. Liss 1979: 469-491.

29. Kellaway P, Hrachovy RA. Status epilepticus in newborns: A perspective on neonatal seizures. In: Advances in Neurology, Vol. 34: Status Epilepticus. Delgado-Escueta AV. Wasterlain CG, Treiman DM, Porter RJ, eds. New York: Raven Press, 1983: 93-99.

30. Svenningsen NW, Blennow G, Lindroth $\mathrm{M}$ et al. Brain-oriented intensive care treatment in severe neonatal asphyxia. Arch Dis Child 1982; 57: 176-183.

31. Boreus LO. Jalling B. Kallberg N. Clinical pharmacology of phenobarbital in the neonatal period. In: Basic and Therapeutic Aspects of Perinatal Pharmacology. Morselli PL, Garattini S. Sereni F, eds. New York: Raven Press, 1975: 331-340.

32. Gamstrop I, Sedin G. Neonatal convulsions treated with continuous intravenous infusion of diazepam. Upsala J Med Sci 1982: 87: 143-149.

33. Homan RW. Walker JE. Clinical studies of lorazepam in status epilepticus. In: Advances of Neurology Vol 34: Status Epilepticus. Delagado-Escueta AV. Wasterlain CG. Treiman DM, Porter RJ. eds. New York: Raven Press, 1983: 493-498.

34. Painter MJ. General principles of treatment. Status epilepticus in neonates. In: Advances in Neurology Vol. 34: Status Epilepticus. Delgado-Escueta AV. Wasterlain CG, Treiman DM. Porter RJ, eds. New York: Raven Press. 1983.

35. Powell C. Painter MJ, Pippenger CE. Primidone therapy in refractory neonatal seizures. J Pediatr 1984: 105: 651-654. 